\title{
Improving Analytical Efficiency of WD Spectrometers using Solid-State Detectors
}

\author{
D. Lesher, D. Lesher III
}

Advanced MicroBeam, Inc. 4217C King Graves Rd., Vienna, Ohio 44473

Wavelength Dispersive Spectrometers have key advantages when analyzing trace elements due to excellent peak to background ratios and energy resolution. However, most WD spectrometers are limited by the x-ray counting capabilities of the gas proportional counters due to saturation and deadtime at higher analytical currents.

WDS solid-state detectors are capable of millions of counts per second with minimal counting system deadtime (Figure 1). By using a solid-state detector, the analyst can adjust the sample current to a magnitude that permits the efficient analysis of the sample, while preventing the saturation of the major elements, in one counting cycle, without changing the size of the analytical volume.

For this analysis, Inconel A690 will be used. Three major elements and 7 trace elements will be analyzed as defined in Table 1. One analysis will be performed using gas proportional counters with lower currents to prevent saturation. The second analysis will be performed using WD solid-state detectors at higher currents in one counting operation per point. The projected total counts for each element will be 50,000. Significant improvement in analytical times will be demonstrated (Figure 2).

Analyzed Elements in Inconel A690 - Weight Percents

\begin{tabular}{|c|c|c|c|c|c|c|c|c|c|c|}
\hline & & & & & & & & & & \\
\hline $\mathrm{Ni}$ & $\mathrm{Cr}$ & $\mathrm{Fe}$ & $\mathrm{Ti}$ & $\mathrm{Al}$ & $\mathrm{Si}$ & $\mathrm{Mn}$ & $\mathrm{Cu}$ & $\mathrm{Nb}$ & $\mathrm{Mo}$ & \\
\hline 58 & 28 & 7 & .2 & .15 & & & & & & $\mathrm{Min} \%$ \\
\hline & 31 & 11 & .45 & .40 & .15 & .5 & .1 & .1 & .1 & $\mathrm{Max} \%$ \\
\hline
\end{tabular}

Table 1 


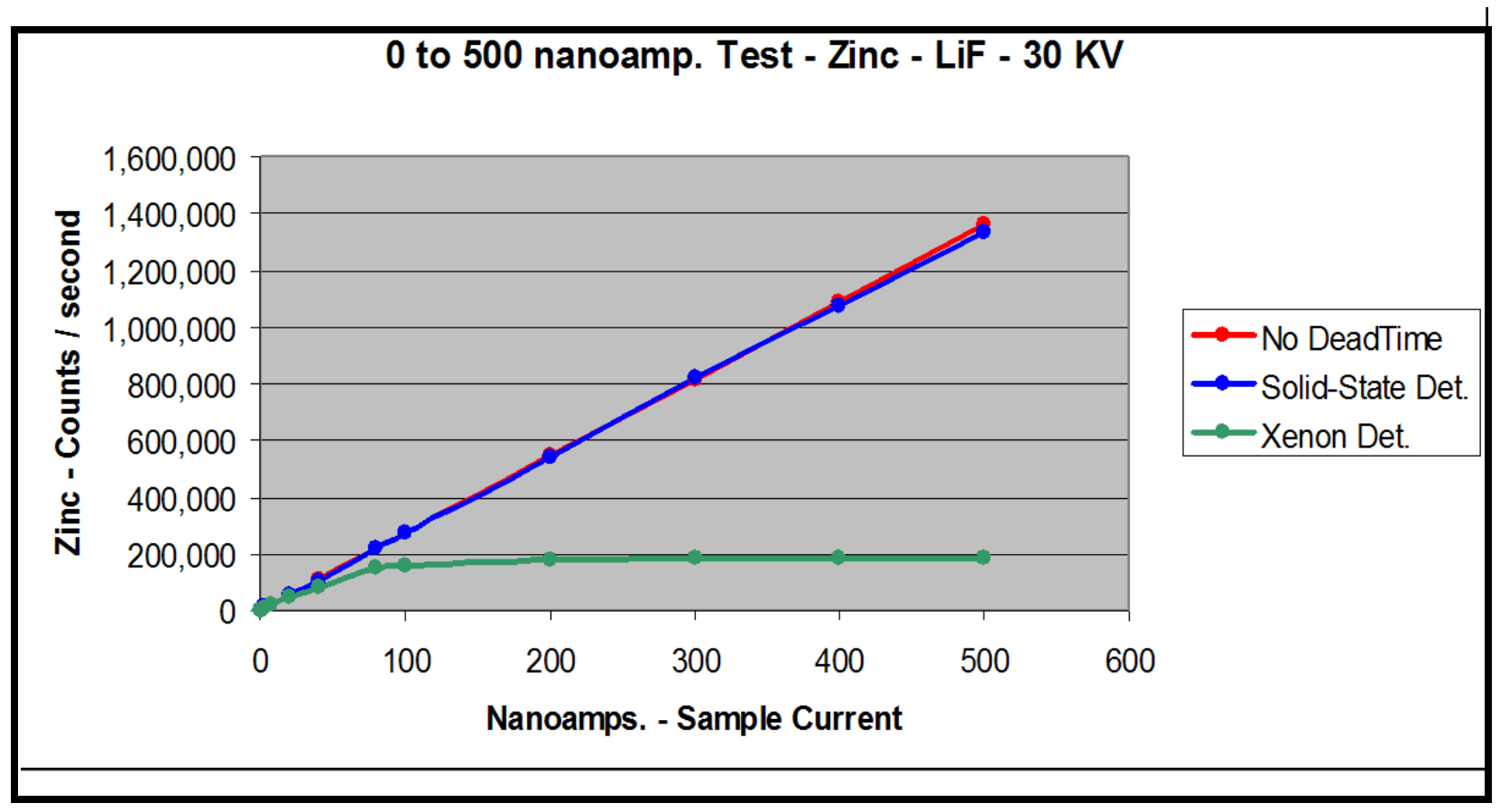

Figure 1. Deadtime Comparison - Solid-State Detector and Xenon

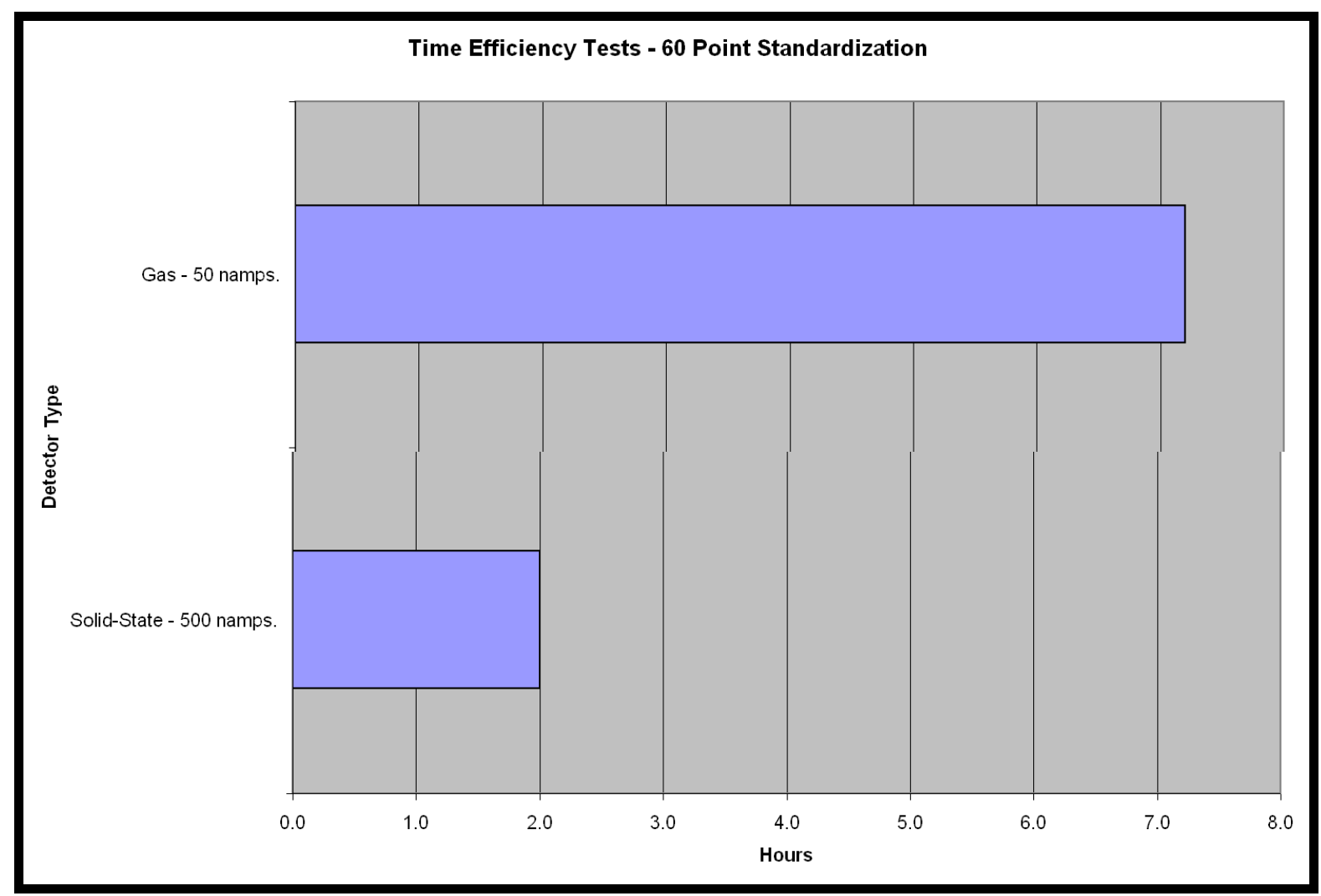

Figure 2. Standardization Time 